\title{
A PRODUÇÃo ESCRITA NO LIVRO DIDÁTICO DE LÍNGUA ESPANHOLA
}

\section{THE WRITTEN PRODUCTION IN THE SPANISH LANGUAGE DIDACTIC BOOK}

\author{
Maria Elia Santos Teixeira*
}

\begin{abstract}
Resumo: Frente ao contemporâneo cenário brasileiro, em relação ao ensino de língua espanhola, o presente estudo tem como tema a produção escrita no livro didático de língua espanhola. Nesse sentido, problematiza-se: de que forma os livros didáticos de espanhol aprovados no Programa Nacional do Livro Didático - PNLD 2015 contribuem para o desenvolvimento das habilidades necessárias à escrita em língua estrangeira? O objeto de estudo diz respeito às propostas de escrita das coleções de Espanhol aprovadas - Enlaces e Cercanía Joven. Objetiva-se, assim, analisar se os livros didáticos de espanhol aprovados no PNLD 2015 contribuem para o desenvolvimento das habilidades necessárias à escrita em língua espanhola. Para tanto, realizamos um trabalho de cunho descritivo, bibliográfico e de base qualitativa. Enquanto considerações finais, entende-se a necessidade de resistência cultural e docente a fim de que seja possível (re)existir frente ao cenário apresentado, bem como avalia-se que é preciso retomar o trabalho da escrita nas aulas de língua espanhola, com o apoio do livro didático.
\end{abstract}

Palavras-chave: Programa Nacional do Livro Didático - PNLD. Ensino. Gêneros do discurso.

\begin{abstract}
Faced with the contemporary Brazilian scenario, in relation to Spanish language teaching, the present study has as its theme the written production in the spanish language textbook. In this sense, the question is: how did the spanish Textbooks approved in the 2015 National Textbook Program contribute to the development of the skills necessary for writing in a foreign language? The object of study concerns the writing proposals of the approved Spanish collections - Enlaces y Cercanía Joven. The purpose of this study is to analyze whether spanish textbooks approved in PNLD 2015 contribute to the development of the skills necessary for writing in spanish. To do so, we carry out a descriptive, bibliographic and qualitative-based work. Final considerations are the need for cultural and educational resistance in order to be possible (re)exist.
\end{abstract}

Keywords: National Textbook Program - PNLD. Teaching. Discourse genres.

\section{Introdução}

As aulas de língua espanhola podem se assumir como um lugar legítimo de ensino da produção escrita, embora seja recorrente professores de espanhol dizerem que a escrita é um processo complexo e, desse modo, nem sempre os docentes desenvolvem atividades que estimulem a produção textual escrita em sala de aula. Não vemos essa crença dos professores como um despropósito: o lugar da língua estrangeira no currículo da escola pública colabora para alimentá-la, e, consequentemente, desmotiválos, ainda mais frente ao atual contexto do ensino dessa língua no Brasil.

Costa (2014, p. 44) traça, em breves palavras, um panorama do ensino de língua espanhola (LE) no Brasil, ao dizer que, de forma geral, o professor costuma não ter “[...] tempo para elaborar outros materiais; tem muitas turmas, de diferentes níveis, e seria

\footnotetext{
* Especialista em Leitura e Produção Textual (UESC), bem como em Língua Espanhola pela Universidade Estadual de Feira de Santana - UEFS. Mestrado em Educação (UESC). Professora de Espanhol do Instituto Federal de Educação, Ciência e Tecnologia Baiano - Campus Uruçuca. Email: mariaelia.carvalho@yahoo.com.br
} 
inviável preparar atividades complementares diversificadas; a disciplina tem apenas uma aula semanal, tornando-se difícil dar conta de todas as unidades do livro". Aliado a esse contexto, destacamos o fato de que no Brasil, durante muito tempo, a língua inglesa é que teve notoriedade - cenário este que passou a se modificar a partir do fortalecimento econômico do país e das relações desenvolvidas de forma mais consolidadas com a América do Sul e a Espanha.

Frente a esse contexto, tivemos, em 2005, a promulgação da Lei 11.611, a qual dispunha como obrigatória a oferta do ensino de língua espanhola nas escolas, sendo facultativa aos discentes a matrícula. Contudo, em 2017, a Lei 13.415 revogou a Lei 11.611, colocando a oferta do ensino de espanhol não mais como obrigatória. Com a aprovação da Lei 13.415/2017, aumentaram ainda mais os desafios para os professores de espanhol e para aqueles que se encontram em formação docente, visto que há desde uma escassez no campo de trabalho a, novamente, uma política linguística de valorização da língua inglesa, em detrimento do espanhol.

Frente a esse cenário, no qual muitos desafios se impõem, nosso tema de estudos é a produção escrita no livro didático de Língua Espanhola. Nesse sentido, por entender que o Livro Didático (LD), geralmente, é a principal fonte de acesso ao conhecimento, em língua estrangeira, para o aluno e para o professor, a questão de pesquisa deste trabalho é: de que forma os Livros Didáticos de espanhol aprovados no Programa Nacional do Livro Didático 2015 contribuem para o desenvolvimento das habilidades necessárias à escrita em língua estrangeira? O objeto de estudo diz respeito às propostas de escrita das coleções de Espanhol aprovadas - Enlaces e Cercanía Joven.

Objetivamos, desse modo, analisar se os Livros Didáticos de espanhol aprovados no PNLD 2015 contribuem para o desenvolvimento das habilidades necessárias à escrita em língua espanhola. Para tanto, realizamos um trabalho de cunho descritivo, bibliográfico e de base qualitativa. No intuito de melhor desenvolvermos nossa análise, o presente estudo foi dividido nas seguintes seções: a presente introdução, na qual apresentamos as linhas gerais de nosso estudo; a segunda seção, por sua vez, busca inter-relacionar o ensino de Língua Espanhola ao PNLD e ao livro didático; já a terceira traz uma análise mais específica de como as coleções estudadas apresentam as atividades de produção escrita e as concepções que subjazem a essa apresentação; por fim, nas considerações finais, retomamos nosso objetivo e reafirmamos a necessidade do trabalho com a escrita nas aulas de Língua Espanhola, bem como que é preciso resistir diante do cenário do ensino de Espanhol no Brasil atualmente.

\section{O Programa Nacional do Livro Didático (PNLD) e o livro didático (LD) no contexto das aulas de Língua Espanhola}

O PNLD é um programa do Governo Federal destinado à avaliação, compra e distribuição de obras didáticas aos alunos da rede pública de ensino. Ao longo de sua história, o programa passou por muitas alterações. Inicialmente foi denominado Instituto Nacional do Livro (INL), cujo objetivo era legislar sobre as políticas públicas do livro didático, bem como aumentar o seu consumo.

O programa passou por um avanço importante em 1995, com a universalização da distribuição do livro didático para os oito anos do ensino fundamental. Já em 1996, o Ministério da Educação autorizou uma avaliação pedagógica das obras didáticas. Desde então, é publicado o Guia do livro didático, que apresenta os critérios usados na seleção 
das obras submetidas ao programa e resenhas das obras aprovadas, a fim de orientar a escolha dos professores.

A partir de 2002, o programa ampliou sua abrangência e distribuição, além de atender ao Ensino Fundamental, em 2003, foi instituído o Programa Nacional do livro didático para o Ensino Médio, passando assim a contemplar a última etapa da escola básica. Nos anos de 2011 e 2012, o PNLD passou a avaliar, comprar e distribuir também obras didáticas em espanhol e inglês para atender alunos e professores do ensino fundamental e do ensino médio.

O crescimento do PNLD promoveu uma ampliação das discussões acerca do livro didático. No nosso entendimento, essa ampliação se justifica, tendo em vista que o governo brasileiro avalia, compra e distribui, gratuitamente, livros didáticos para todos os alunos das escolas públicas. Assim, quanto mais pesquisas, mais chances de produzirmos livros que atendam às demandas de professores e alunos.

O LD propicia aos principais sujeitos envolvidos no ensino/aprendizagem - o professor e o aluno - uma comodidade, especialmente, por apresentar uma formatação já pensada em um modelo de ensino, dividida em conteúdos que se distribuem por unidades. É importante dizer que, por vezes, essa formatação mostra-se inadequada à realidade do aluno. Segundo Batista (2008), os projetos gráficos dos manuais didáticos costumam ser pouco inovadores, formatando o LD como uma "caixinha pronta". Embora as considerações de Batista sejam sobre o LD de língua portuguesa, avaliamos que elas também podem ser aplicadas ao contexto do LD de língua espanhola:

[...] os livros didáticos tendem a apresentar não uma síntese dos conteúdos
curriculares, mas um desenvolvimento desses conteúdos; a se caracterizar
não como um material de referência, mas como um caderno de atividades
para expor, desenvolver, fixar e, em alguns casos, avaliar o aprendizado;
desse modo tendem a ser não um apoio ao ensino e ao aprendizado, mas um
material que condiciona, orienta e organiza a ação docente, determinando
uma seleção de conteúdos, um modo de abordagem desses conteúdos, em
suma uma metodologia de ensino, no sentido amplo da palavra (BATISTA,
2008, p. 47).

Em salas de aula de espanhol, o LD assume um papel ainda mais importante do que em salas de aula de língua materna, em função da dificuldade de acesso a outras fontes de recursos didáticos em língua espanhola. No entanto, é preciso admitir que, na última década, o acesso a textos variados tem sido facilitado pelas novas mídias. Neste trabalho, não defendemos que o professor se torne um refém do $L D$, ou como diz Gimenez (2009), não defendemos que o professor se transforme em um "fiel seguidor" do livro escolhido (p. 8), visto como portador de conhecimentos inquestionáveis. Tampouco defendemos que se promova uma verdadeira "caça às bruxas" ao LD e que ele seja abolido das aulas de LE.

Defendemos seu uso de forma crítica, o que, para nós, significa que o professor deve usar o livro didático sem perder de vista o contexto de sua sala de aula. Os LDs não podem ser confundidos com a própria aula; eles são recursos didáticos e o professor precisa de autonomia e conhecimento suficientes para adaptá-los. Vale destacar que, essa autonomia é indispensável na construção do protagonismo do aluno.

Se nos fosse perguntado qual seria o livro didático ideal, provavelmente responderíamos que é aquele que abre lugar para os sujeitos do processo de ensinoaprendizagem, os professores e os alunos. Essa resposta faz da tarefa de elaborar materiais didáticos um conjunto de decisões bastante complexo: quais textos selecionar? Como construir e dispor os enunciados? Como elaborar um projeto gráfico afinado com 
as concepções teórico-metodológicas da obra? Como organizar os conteúdos? Quais concepções teóricas utilizar? Barros e Costa (2010) evidenciam essa complexidade:

\begin{abstract}
Os materiais didáticos são construídos a partir de concepções metodológicas e, embora nem sempre estas sejam explicitadas, acabam transparecendo de alguma forma, tornando evidentes os conceitos que estão em sua base: o que se entende por língua, ensino e aprendizagem; percepções dos papéis de professores e alunos; uma determinada visão da dinâmica que deve propiciar a aquisição de conhecimentos. Essas concepções se revelam no fio condutor das unidades (temas, conteúdos gramaticais, funções, tarefas), na organização dos conteúdos, nos textos usados como amostras de uso e funcionamento da língua, no tipo de exercícios propostos etc., e, via de regra, determinam e condiciona o processo de ensino/aprendizagem que será posto em prática na sala de aula. (BARROS; COSTA, 2010, p. 89)
\end{abstract}

As considerações feitas até aqui nos fazem refletir sobre a importância da escolha e do uso do livro didático pelos professores. A escolha não pode se dar tão somente pelo quão atrativo é o projeto gráfico ou pelos tópicos gramaticais; a escolha deve observar, a nosso ver, três pontos: os critérios que conduziram a análise da obra pelo PNLD, a adequação da proposta implementada na obra às suas concepções de ensino-aprendizagem, a realidade de sua sala de aula. Tampouco o uso pode se dar de forma aleatória, como se o livro não passasse de um amontoado de papeis impressos. $\mathrm{O}$ uso precisa considerar o trabalho realizado pelos autores; o que não significa que o professor não possa e não possa "pular" atividades, adaptar e até elaborar outras - isso, no entanto, não pode acontecer sem que o professor tenha a clareza sobre os princípios teórico-metodológicos que sustentam seu trabalho.

O PNLD, através do Guia de Livro Didático, disponibiliza para os professores as resenhas dos LDs aprovados. Esse é um dos instrumentos que o professor tem à sua disposição para ajudá-lo na escolha do manual que melhor representa a sua concepção de ensino. Sem dúvida, a escolha é um passo de fundamental importância, já que, por três anos, o professor fará uso da coleção escolhida. A importância também se deve ao fato de o livro didático representar algo mais do que um conjunto de orientações pedagógicas, como assinalam Daher, Freitas e Sant'Anna (2013, p. 408):

O livro didático, então, longe de ser um mero material de apoio, é um registro privilegiado do que em determinado momento da história pode ser dito e, como consequência, sobre o que se silencia. Entendemos o LD, ainda, como uma produção vinculada a valores, a posições ideológicas, visões de língua, de ensino de língua, de aluno, de professor, e de papel das línguas estrangeiras na escola.

De acordo com o PNLD/2015 pg. 9, o livro didático de língua estrangeira precisa proporcionar o "engajamento discursivo" do aprendiz e, ao mesmo tempo, também contribuir para sua formação intelectual e cidadã. O Guia destaca que as coleções aprovadas passam por um "longo e criterioso processo de trabalho", realizado por profissionais que trabalham do Ensino Médio ao Superior, com atuação na rede pública de ensino, nos diversos estados do país.

Conforme Daher e Sant'Anna (2016), quando, em 2005, o governo publicou um edital de convocação de editoras interessadas em participar de um processo de seleção de material didático de Língua Espanhola, destinado aos professores de escolas públicas de ensino médio, houve um flagrante descompasso entre as expectativas do governo e a qualidade do material avaliado: 


\begin{abstract}
Foram avaliadas diferentes categorias de obras: gramáticas impressas de língua espanhola; dicionários monolíngues espanhol/espanhol; dicionários bilíngues espanhol/português e português/espanhol; e livros impressos para professor de língua espanhola. O resultado da avaliação comprovou um forte descompasso entre as expectativas do MEC e o que o mercado editorial ofereceu. Das 13 gramáticas inscritas, apenas duas foram aprovadas; dos 14 dicionários monolíngues, cinco foram selecionados; dos 14 dicionários bilíngues, só dois foram recomendados; e no que se refere a livros para o professor, entre as 21 coleções inscritas somente quatro foram indicadas para a compra (DAHER; SANTANA, 2016, p. 98).
\end{abstract}

Esse descompasso, pelo visto, persiste, tendo em vista que, das coleções de língua espanhola submetidas ao PNLD 2015, apenas um número pequeno foi aprovado, cerca de $15 \%$, enquanto $85 \%$ foi excluído do processo de seleção/avaliação. Achamos também necessário apresentar a concepção de escrita e gênero, bem como os critérios de avaliação da produção escrita nos livros, de acordo com o edital do PNLD para 20152018. Conforme o Edital de convocação para o processo de inscrição e avaliação de obras didáticas para o PNLD 2015, a visão de ensino médio do edital coaduna com a proposta pelos documentos oficiais que parametrizam a educação nacional, a saber: Parâmetros Curriculares Nacionais (PCN) (1997), Parâmetros Curriculares Nacionais + (PCN+) (2002), Orientações Curriculares para o Ensino Médio (OCEM) (2006) - no caso do Ensino Médio, e Leis de Diretrizes e Bases da Educação Nacional (LDB) (1996). O edital do PNLD sinaliza que o principal objetivo da Língua Estrangeira "[...] é contribuir para a formação de cidadãos engajados com o seu entorno e com o de outras realidades sociais. Esse engajamento deve pautar-se em princípios e valores éticos que preparem para o exercício da cidadania" (BRASIL, 2013, p. 46).

Para o Edital, as coleções aprovadas necessitam viabilizar o acesso aos gêneros do discurso, assim como prover "[...] situações nas quais a fala e a escrita possam ser aprimoradas a partir da compreensão de suas condições de produção e circulação, bem como de seus propósitos sociais" (BRASIL, 2013, p. 46). Com relação aos critérios de exclusão relacionados à produção escrita o edital chama a atenção que os manuais devem promover atividades de escrita, que a considerem como processo interacional, destacando a definição de projeto de comunicação (quem, para quem, com que objetivos), bem como entender que "[...] a escrita se pauta em convenções relacionadas a contextos e gêneros de discurso e está submetida a processo de reescrita do próprio texto" (BRASIL, 2013, p. 47). Para o documento, a leitura e a escrita necessitam ocupar um lugar central na aprendizagem da língua estrangeira, e, nesse contexto, os manuais devem desenvolver atividades de leitura, escrita e oralidade, as quais integrem propósitos e finalidades da aprendizagem da língua estrangeira (BRASIL, 2013).

\title{
3 Concepções de língua, texto, gênero e escrita nas coleções aprovadas no PNLD $/ 2015$
}

Nesta seção, buscamos identificar as concepções de língua, de texto, de gênero e de escrita apresentadas pelas coleções no Manual do Professor (MP). Isso é importante, especialmente, para verificar se há coerência entre os pressupostos teóricometodológicos declarados e a proposta desenvolvida no Livro do Aluno (LA). Em outras palavras, o que elas anunciam que vão fazer é o que realmente fazem? 


\subsection{Coleção Cercanía Joven}

Cercanía Joven, de Ludmila Coimbra, Luíza Chaves e Pedro Barcia (2013), é uma coleção composta por três volumes e por um CD de áudio, destinada ao Ensino Médio. Cada volume se organiza em três unidades, que se distribuem em seis capítulos. No manual do professor, a coleção apresenta os fundamentos teórico-metodológicos que, segundo os autores, orientaram a escrita da obra. De acordo com os autores, a coleção Cercanía Joven se propõe a:

- elegir temas de mediación entre el mundo escolar y el mundo extraescolar;

- abordar asuntos relevantes para la franja etaria meta;

- presentar actividades desafiadoras, motivadoras, interesantes y lúdicas;

- trabajar la lengua en uso y el vocabulario en contexto, insertados en los géneros textuales y en los actos de habla;

- utilizar una gran variedad de géneros discursivos presentes en diversas esferas de circulación (periodística, literaria, publicitaria, cotidiana, jurídica etc.);

- enseñar la lengua extranjera en articulación con otros saberes, como una fuente más de investigación y de construcción de conocimientos, bajo un enfoque interdisciplinario y transversal. (COIMBRA; CHAVES; BARCIA, 2013, p. 208)

Os autores dizem assumir uma visão de língua como "[...] un sistema organizado en tres subsistemas que se imbrican: el linguístico, el semántico y el discursivo" (COIMBRA; CHAVES; BARCIA, 2013, p. 210). No MP, os autores afirmam que é importante compreender os vínculos da língua com a cultura, uma vez que os hábitos diários, as manifestações religiosas, as festividades, as características ambientais, as tradições, os mitos, dentre outros, se dão pela e na linguagem. Eles também defendem que é importante que a aprendizagem da língua estrangeira aconteça numa perspectiva intercultural, pois, no processo de ensino-aprendizagem, seria necessário que, o aluno pudesse "[...] reconocer al otro y estar disponible para actuar de forma mediadora haciendo que haya valoración de los conocimientos previos y actualización de otros saberes es hacer que el otro se reconozca a partir de otras visiones" (COIMBRA; CHAVES; BARCIA, 2013, p. 211). Ainda no que se refere à concepção de língua, a coleção defende o respeito à variedade linguística, em dois tópicos: "¿Enseñar el español pensinsular o latinoamericano?” $e$ “Enseñar el español de un grupo social o un español estándar?”, concluindo que todas as variedades devem ser contempladas.

$\mathrm{O}$ conceito de gênero apresentado no MP é o de Bakhtin, os autores declaram que a coleção se propõe a trabalhar com a diversidade de gêneros, de esferas e com as condições de produção, o que justificaria, segundo os mesmos, a presença, no livro do aluno, de um quadro que explicita o gênero, os prováveis leitores, o tema e o tipo de produção (se individual, em dupla, em grupo). O MP não apresenta a concepção de texto da obra. O manual fala em três modelos de concepção de escrita: a primeira, cujo foco é a própria língua; a segunda, cujo foco é o autor do texto; e a terceira, que focaliza a interação. Embora não declare explicitamente, subentende-se que a obra defende a terceira concepção. Segundo os autores, "[...] Mediante ese enfoque en los géneros textuales, un modelo de enseñanza de la producción escrita es la secuencia didáctica 
propuesta por Dolz, Noverraz y Schneuwly" (COIMBRA; CHAVES; BARCIA, 2013, p. 209).

\subsection{Coleção Enlaces}

Enlaces, de Soraia Osman, Neide Elias, Priscila Reis, Sonia Izquierdo e Jenny Valverde (2013), é uma coleção para o ensino médio, composta por três volumes e por um CD de áudio, por um livro digital e por objetos educacionais digitais (OED). Cada volume se organiza em oito unidades. No manual do professor, a coleção apresenta suas concepções teórico-metodológicas.

Segundo as autoras da coleção, a proposta didática do Enlaces segue os princípios dos Parâmetros Curriculares Nacionais para o Ensino Médio (PCNEM), das Orientações Educacionais Complementares aos Parâmetros Curriculares Nacionais: Linguagens, Códigos e suas Tecnologias, das Orientações Curriculares para o Ensino Médio (OCEM) e da matriz de referência para o Exame Nacional do Ensino Médio (Enem).

Ainda de acordo com as autoras, a coleção apresenta:

- temas que permiten desarrollar el sentido crítico y el respeto a los diferentes valores culturales y sociales;

- desarrollo de las competencias y habilidades linguísticas, procedimentales y de actitud;

- muestras auténticas de lengua;

- análisis sistematizado y producción de géneros discursivos orientados;

- enfoque intercultural;

- aprendizage significativo;

- autoevaluación como una actividad metacognitivo y propuesta de autorregulación del aprenizaje. (OSMAN et al., 2013, p. 211).

Para as autoras, é imprescindível, na produção do material didático de língua estrangeira, ter clareza do conceito de língua subjacente ao material. Ancorando-se em Rajagopalan, as autoras propõem a língua como uma entidade essencialmente geopolítica, isto é, ao se conhecer uma língua não se podem descartar as construções político-linguísticas que resultam do padrão e da relativa fixação na gramática e dicionários "[...] y que alcanzan una denominación mundial”" (OSMAN et al., 2013, p. 213). A coleção Enlaces também anuncia que uma de suas preocupações é a variação linguística e "[...] el funcionamento de la lengua privilegiando la producción de sentido, pero sin eludir los niveles de ese funcionamento que muestran un grado de sistematicidade necesario" (OSMAN et al., 2013, p. 213). Elas afirmam, ainda, que a coleção não privilegia os usos da língua de determinado país ou região.

A concepção de gênero apresentada no MP, e na coleção Cercanía Joven, é a bakhtiniana. O texto é definido como "[...] una unidad de comunicación, o sea, no lo podemos entender como un conjunto de frases, sino a partir de las relaciones entre varios de sus componentes" (OSMAN et al., 2013, p. 218). O MP não apresenta a concepção de escrita da obra, no entanto os elementos para-textuais (título, subtítulo, o desenho e o tamanho das letras, a pontuação, dentre outros) receberão atenção especial, pois " [...] siendo el paratexto un expediente propio del texto escrito y que nace con el advenimiento de la escritura para orientar la lectura, la explicación sistemática de sus componentes se muestra útil en las actividades" (OSMAN et al., 2013, p. 220). 


\subsection{Como as coleções trabalham com os tópicos de escrita avaliados pelo PNLD}

Entre os livros didáticos aprovados no PNLD 2015, uma coleção dá mais destaque à escrita do que a outra. Iremos agora apresentar a organização das duas coleções aprovadas.

Cada livro da coleção Cercanía Joven possui em sua estrutura três unidades que se dividem em seis capítulos, cada capítulo se subdivide nas Seções: Lectura, Habla, Escucha e Escritura. O gênero a ser trabalhado aparece em todas as seções. Geralmente é destinado uma média de sete páginas para o trabalho com a produção escrita na seção escritura, a qual apresenta um box informando para o aluno o projeto de comunicação a ser desenvolvido. Ainda nesta seção há as seguintes subseções: conociendo el género, planeando las ideas, vocabulario en contexto, gramática en uso, taller de escritura e (re)escritura.

Os manuais da coleção Enlaces apresentam a seguinte estrutura: Cada manual possui oito unidades, cada unidade se inicia com os objetivos a serem alcançados pelo aluno. As unidades apresentam as seguintes subseções: Hablemos de..., Y no solo esto!, Manos a la obra!, Espanhol vs. Portugues, En otras palavras..., Como te decía..., Nos...otros e Así me veo . A produção escrita é trabalhada na subseção En otras palabras, uma página é destinada para o trabalho com a escrita.

A seguir iremos conhecer como as duas coleções aprovadas trabalham a produção escrita de acordo os avaliadores do programa. É importante lembrar que a primeira vez que o componente curricular Língua Estrangeira Moderna fez parte do PNLD foi em 2011, para atender à Lei de Diretrizes e Bases (LDB) 9394/96. Portanto, em 2015, registramos a segunda edição do PNLD de línguas estrangeiras. Veremos, a seguir, os critérios de análise do eixo da produção escrita e como o PNLD/2015 avaliou as duas coleções aprovadas em Língua Espanhola.

A avaliação do PNLD é realizada a partir de uma ficha, que traz os critérios gerais e específicos que devem ser seguidos pelos avaliadores das coleções. A ficha do PNLD 2015 de língua estrangeira foi organizada em duas partes: Parte A (critérios teórico-metodológicos comuns e específicos de Língua Estrangeira Moderna) e a Parte B (critérios comuns relativos ao respeito à legislação, diretrizes e normas oficiais relativas ao ensino médio e à observância de princípios éticos e democráticos necessários à construção da cidadania e ao convívio social republicano). Cada parte está organizada em blocos, que trazem os itens de avaliação. Os itens da ficha parecem ter sido inspirados no edital do programa, que afirma que as coleções devem promover atividades de produção escrita, que a consideram como processo de interação, que exige "definição de parâmetros comunicativos (quem, para quem, com que objetivos), entendimento de que a escrita se pauta em convenções relacionadas a contextos e gêneros de discurso e está submetida a processo de reescrita do próprio texto" (Edital PNLD 2015, p. 47).

No nosso entendimento, embora assuma a escrita como processo - item $14-$, aponte para a necessidade de se representarem as diferentes comunidades falantes do espanhol - item 15 - e destaque a importância da etapa de reescrita no processo - item 16 -, o Guia não traz critérios que avaliam se o LD colabora, com o aluno, na construção: i) do conteúdo temático do texto, ii) da materialidade linguística do texto, iii) da forma composicional, iv) de um texto adequado às convenções da escrita. Considerando-se que a ficha sofre a influência da definição de gênero proposta pelo 
Círculo de Bakhtin, cria-se a expectativa de que, em seus critérios de análise, apareçam elementos que apontem para a concepção de gênero defendida pelos estudiosos russos.

Os poucos critérios para avaliação da produção escrita resultam, a nosso ver, em dificuldades para distinguir o trabalho proposto pelas coleções nas resenhas do guia, embora Enlaces e Cercanía Joven sejam significativamente diferentes no que se refere ao ensino da escrita - essas diferenças se evidenciam, inclusive, pelo espaço físico dedicado à escrita em cada coleção: uma página, no Enlaces; e cinco páginas, em média, no Cercanía Joven.

É importante dizer que, na seção "Em sala de aula" da resenha do guia, não se faz qualquer observação quanto ao eixo da produção textual escrita. Dizemos isso porque, tradicionalmente, essa seção aponta aquilo que o professor precisa fazer para complementar o trabalho da coleção. Feitas essas considerações sobre as partes da ficha da resenha do PNLD 2015 que remetem à produção escrita, passamos à análise das coleções.

Cercanía Joven propõe três produções escritas por ano, uma por unidade. Todas elas são acompanhadas por um quadro que sintetiza os elementos do projeto de comunicação que deve ser desenvolvido pelos alunos. Quando, por exemplo, o gênero textual é a sinopse literária, conforme consta no Livro II, unidade I, são informados aos alunos os seguintes pontos: Objetivo de escrita - recomendar um livro literário; Tema livre; Tipo de produção - individual; Leitores - frequentadores da biblioteca da escola.

Embora as informações apresentem o gênero, o objetivo, o tema, o tipo de produção e leitores, destacamos que em nenhuma das três propostas que constam no LD, há a indicação ao aluno que simule um outro lugar social - é sempre o aluno, e não um jornalista, um editor de livros, um chargista. Simular o lugar social de "quem" escreve pode ser fundamental para extrapolar a escolarização excessiva das atividades de produção textual.

Por sua vez, Enlaces propõe oito produções escritas por ano, uma por unidade. Embora não esteja explicitado, quase sempre é possível inferir o objetivo e os possíveis leitores das propostas de escrita da coleção. Entretanto, é preciso considerar que: muitas vezes, o leitor indicado é o colega de classe, conforme os exemplos acima; nos casos em que não é possível inferir o objetivo, o aluno pode não se sentir motivado a escrever: para que, por exemplo, vai elaborar uma ficha, relacionando os principais problemas observados no trajeto entre sua casa e a escola? Parece-nos que o objetivo, dessa proposta, de fato, é o exercício da língua.

Nossa análise, até aqui, nos permite dizer que, embora as duas coleções se declarem sociointeracionistas, a abordagem da escrita como processo é mais delineada na coleção Cercanía Joven. Quanto a isso, a análise que fizemos vai ao encontro da análise da coleção apresentada no Guia do PNLD 2015 (BRASIL, 2014), que apontou o trabalho processual como o destaque da coleção. Já a coleção Enlaces, de acordo com nossas observações, ainda não consolidou essa mudança de paradigma no tratamento da produção textual escrita: atravessa um entre-lugar - entre o produto e o processo.

Com relação à representatividade das diversas comunidades de falantes da língua, defendida pelo Guia, pode-se dizer que as duas coleções atendem a essa exigência, embora a coleção Cercanía Joven (Argentina, Chile, Colômbia, Espanha, Honduras, México, Peru) apresente uma diversidade maior de textos de países que falam o espanhol em sua seção de escrita do que a coleção Enlaces (Argentina, Chile, Espanha, México). Nesta, na seção de produção textual, há um número significativo de textos não autênticos e de textos adaptados. No nosso entendimento, seria importante que esse critério apresentasse pelo menos um desdobramento: considerando-se que há variações 
significativas do espanhol falado em várias partes do mundo, em suas seções de escrita, os LDs poderiam solicitar ao menos uma produção situada, isto é, que levasse em conta as variedades da língua de um país para outro.

No que diz respeito à reescrita, as coleções aprovadas apresentam diferenças significativas, sobretudo se prestarmos especial atenção à ficha do PNLD 2015,(pg. 17) que pergunta se a coleção "contém atividades que promovem o processo de reescrita do próprio texto". Entretanto, a resenha do guia do PNLD 2015(pg 27), surpreendentemente, não destaca o processo de reescrita, que é um dos critérios da ficha: com relação à coleção Enlaces, não se faz qualquer comentário; com relação à coleção Cercanía Joven, diz "ao final, é incentivada a reescrita do texto". A resenha faz supor que a primeira não menciona o processo de reescrita e que a segunda trata disso timidamente - a nosso ver, nenhuma das duas suposições é verdadeira.

\section{Considerações finais}

Não se pode negar que, fazendo um recorte dos últimos anos, houve um avanço considerável na qualidade de produção dos LDs de Língua Espanhola. Os autores e editoras de livros didáticos têm procurado atender às demandas e orientações dos documentos oficiais no que diz respeito ao ensino/aprendizagem de Língua Estrangeira. No entanto, isso não nos impede de, na condição de professoras/pesquisadoras, contribuir com análises, questionamentos, inquietações, enfim, provocações que, tomara, se somem às pesquisas desenvolvidas na área. É provável que nossas conclusões carreguem equívocos, entretanto, ratificamos que nosso objetivo é acrescer às pesquisas que investigam a produção escrita nos livros didáticos de espanhol.

Quanto ao nosso objetivo, nossa análise nos autoriza a dizer que a coleção Cercanía Joven aborda a escrita na perspectiva do processo e a coleção Enlaces aborda a escrita numa perspectiva em transição do produto para o processo. No manual do professor, a coleção Cercanía Joven anuncia uma concepção de língua como um sistema organizado em três subsistemas: o linguístico, o semântico e o discursivo. Os autores da coleção também anunciam um ensino de língua a partir dos gêneros, com base teórica no interacionismo sócio discursivo, e com abordagem metodológica baseada na sequência didática desenvolvida pelo Círculo de Genebra.

Nossa análise nos permite dizer que o projeto de ensino da produção escrita desenvolvido no livro do aluno da coleção Cercanía Joven é coerente com o que foi anunciado no manual do professor, a ponto de a resenha do guia do PNLD apontá-lo como o destaque da coleção: nas oficinas de produção, há atividades que orientam os alunos na construção de textos, considerando tanto o subsistema discursivo, como o semântico e o gramatical; nessas atividades, reconhecem-se tanto a teoria sóciointeracionista como uma organização que toma como referência as partes da sequência didática de Dolz, Schneuwly e Noverraz; a cada capítulo, um gênero é tomado como objeto de ensino-aprendizagem.

No manual do professor, a coleção Enlaces define língua como uma entidade geopolítica associada às construções político-linguísticas que resultam do padrão e da relativa fixação na gramática e nos dicionários. A nosso ver, há uma lacuna com relação às concepções teórico-metodológicas que sustentam o trabalho com a escrita na obra. Embora, no MP, ao destacar o trabalho com os gêneros, as autoras falem sobre a importância de se reconhecerem suas regularidades e os elementos indicativos de coesão, nas atividades de produção escrita, esses aspectos não são retomados 
reflexivamente. A coleção Enlaces faz a opção por uma abordagem mais transmissiva no trabalho com a produção textual: o foco está na forma composicional e em alguns recursos estilísticos recorrentes no gênero apresentado. A nosso ver, a obra pratica muito mais uma metalinguagem do gênero em detrimento do uso do mesmo, o que caracterizaria uma prática epilinguística. A nosso ver, a coleção privilegia o "mandar escrever", o que fica evidenciado no número de propostas de produção por volume: oito. Se considerarmos que, em geral, uma turma tem uma ou duas aulas de espanhol por semana, torna-se muito difícil que sejam trabalhados na perspectiva do "ensinar a fazer" oito gêneros por ano.

As questões até aqui delineadas nos levam a concluir que, conforme, anunciamos no início deste trabalho, escrever é algo complexo, é um desafio para a escola, professores, pesquisadores, manuais didáticos e acima de tudo para o aluno. Entendemos ainda que o desafio é de todos nós, envolvidos neste processo, pois é necessário viabilizar meios para promover o desenvolvimento da escrita através de atividades de ensino, ainda mais no contexto contemporâneo do ensino de língua espanhola no Brasil, como apresentado na Introdução. Tal contexto nos leva a entender que precisamos resistir e fazer das nossas salas de aula um ponto de reflexão e de afirmação tanto da cultura espanhola (em suas variadas modalidades) quanto de ensino e aprendizagem da língua espanhola.

\section{REFERÊNCIAS}

BARROS, S. C.; COSTA, E. G. M. (Orgs.). Espanhol: Ensino Médio. Brasília: MEC/SEB, 2010. v. 16. (Coleção Explorando o Ensino).

BATISTA, A. A. A Avaliação dos Livros Didáticos: Para entender o Programa Nacional do Livro Didático (PNLD). In: ROJO, R.; BATISTA, A. A. (Orgs.). Livro Didático de Língua Portuguesa, Letramento e Cultura da Escrita. Campinas: Mercado de Letras, 2008.

BRASIL. Secretaria de Educação Fundamental. Parâmetros curriculares nacionais : introdução aos parâmetros curriculares nacionais / Secretaria de Educação Fundamental. - Brasília : MEC/SEF, 1997.

. Secretaria de Educação Média e Tecnológica. PCNs+ Ensino Médio:

orientações educacionais complementares aos Parâmetros Curriculares Nacionais. Brasília : MEC/SEF, 2002.

. Linguagens, códigos e suas tecnologias / Secretaria de Educação Básica. Brasília: (Orientações curriculares para o ensino médio ; volume 1)

Ministério da Educação, Secretaria de Educação Básica, 2006.

- Edital de convocação para o processo de inscrição e avaliação de obras didáticas para o Programa Nacional do Livro Didático - PNLD 2015. Brasília: MECSEB, 2013. Disponível em: https://www.fnde.gov.br/programas/programas-dolivro/consultas/editais-programas-livro/item/4032-pnld-2015. Acesso em: 03 jan. 2019. 
. Guia de Livros Didáticos: PNLD 2015 - Língua Estrangeira moderna: ensino médio. Brasília: Ministério da Educação, Secretaria de Educação Básica, 2013.

. Lei de Diretrizes e Bases da Educação Nacional. Brasília, 1996. Disponível em: < http://portal.mec.gov.br/arquivos/pdf/ldb.pdf > Acesso em: 10/03/16.

. Lei $\mathrm{n}^{\mathrm{o}}$ 11.161/05 de 05 de agosto de 2005. Brasília. Disponível em: < http://www.planalto.gov.br/ccivil_03/_Ato2004-2006/2005/Lei/L11161.htm> Acesso em: 10/03/16.

COIMBRA, L.; CHAVES, S.L.; BARCIA, L.P. Cercanía Joven. Volumes 1, 2, 3. São Paulo: SM, 2013.

COSTA, E.G.M. Que livro didático nós queremos? Reflexões a partir do PNLD de Língua Estrangeira. In: CORDEIRO, A. L., VARGENS, D. P. M.; FREITAS, L. M. A.; VASQUEZ, R. P. (Orgs). Hispanismo no Brasil: reflexões e sentidos em construção. São Carlos: Pedro \& João editores, 2014. p. 43 a 82.

DAHER, D. C.; FREITAS, L.; SANT'ANNA, V. Breve trajetória do processo de avaliação do livro didático de língua estrangeira para a educação básica no âmbito do PNLD. Revista Eutomia, Recife: UFPE, v. 1, n. 11, p. 407-426, Jan./Jun., 2013.

DAHER, D. C.; SANT'ANNA, V. Avaliação do livro didático de língua estrangeira: em busca de um objeto ético. In: BARROS, C. COSTA, E. e GALVÃ̃O, J. (Orgs). Dez anos da "Lei do Espanhol" (2005 - 2015). Belo Horizonte, 2016.

GIMENEZ, T. Prefácio: In: DIAS, R.; CRISTOVÃO, V. L. L. (Org.). O livro didático de língua estrangeira. Múltiplas perspectivas. Campinas, SP: Mercado de Letras, 2009. p. 8.

OSMAN, S.; ELIAS, N.; REIS, P.; IZQUIERDO, S. e VALVERDE, J. Enlaces: español para jóvenes brasileños. Volumes 1, 2, 3. São Paulo. Macmillan.2013.

Recebido em 23 de fevereiro de 2019

Aceito em 13 de maio de 2019 